\section{Comment on "Global Genetic Change Tracks Global Climate Warming in Drosophila subobscura"}

\author{
Francisco Rodríguez-Trelles ${ }^{1 *}$ and Miguel Ángel Rodríguez ${ }^{2}$
}

Balanyà et al. (Reports, 22 September 2006, p. 1773) build on earlier claims that chromosomal inversion polymorphisms of Drosophila subobscura are rapidly evolving in response to global warming. However, that conclusion is not adequately buttressed by their data, because they overlooked the lag between calendar and climatological dates created by the progressive lengthening of the growing season in their sampling approach.

$\mathrm{B}$ alanyà et al. (1) recently appraised the hypothesis that chromosomal inversion polymorphisms of Drosophila subobscura are evolving in response to global warming. (2-4). However, their conclusions may not be adequately supported by their data owing to a potential systematic bias in their sampling approach. Balanyà et al. compared inversion frequency records collected up to 50 years ago latitudinally across three continents with the corresponding current records

${ }^{1}$ Grupo de Medicina Xenómica, Hospital Clínico Universitario, Universidade de Santiago de Compostela, 15706 Santiago, Spain. ${ }^{2}$ Department of Ecology, University of Alcalá, 28871 Alcalá de Henares, Madrid, Spain.

*To whom correspondence should be addressed. E-mail: ftrelles@usc.es

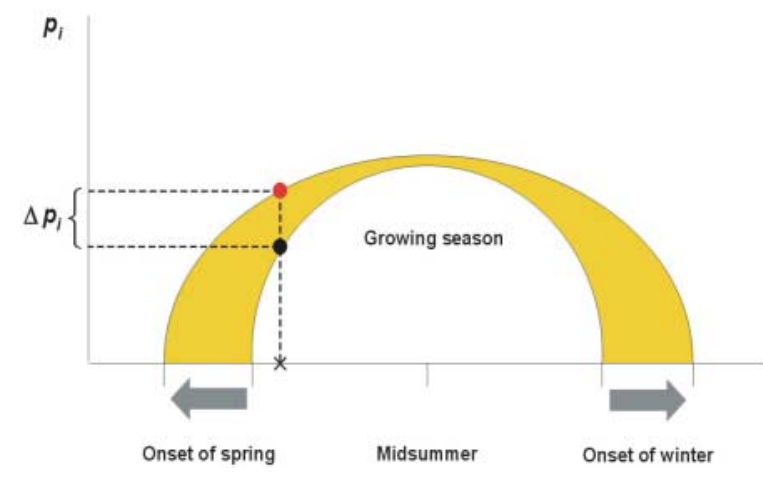

Fig. 1. Schematic depiction of the hypothetical influence of a lengthened growing season on the seasonal cycle $\left(p_{i}\right)$ of a typically southern inversion in the Northern Hemisphere (9). Inversion frequencies begin to rise earlier in spring and to decline later from midsummer in the present (outer cycle) than historically (inner cycle). Sampling the same calendar date (red dot) as in the past (black dot) gives frequencies that are systematically upwardly shifted $\left(\Delta p_{i}\right)$ with respect to the old ones, despite no change in the long-term level of the inversion. ing number of studies of biological responses to global warming will rely on updates of old measurements. Taking into account the progressive lengthening of the growing season in deciding new sampling dates should help to obtain more precise records.

References and Notes

1. J. Balanyà, J. M. Oller, R. B. Huey, G. W. Gilchrist, L. Serra, Science 313, 1773 (2006).

2. F. Rodríguez-Trelles, M. Á. Rodríguez, Evol. Ecol. 12, 829 (1998).

3. F. Rodríguez-Trelles, M. Á. Rodríguez, S. M. Scheiner, Conserv. Ecol. 2, 2 (1998).

4. J. Balanyà, E. Solé, J. M. Oller, D. Sperlich, L. Serra, J. Zool. Syst. Evol. Res 42, 191 (2004).

5. Indeed, this is not always the case. For example, for the Palearctic data, only 6 of the 13 new samples date to the same month as their historical records. The remaining seven comparisons include two for which old dates are uncertain or unknown and four in which the new samples were taken 1 to 2 months nearer mid-summer than the old ones. Those four comparisons are particularly troublesome, because they are expected to create the false impression of a long-term shift toward a more southern configuration if southern inversions reach their annual peak in summer $(9,10)$.

6. R. B. Myneni, C. D. Keeling, C. J. Tucker, G. Asrar, R. R. Nemani, Nature 386, 698 (1997).

7. C. Parmesan, Annu. Rev. Ecol. Syst. 37, 637 (2006).

8. W. E. Bradshaw, C. M. Holzapfel, Science 312, 1477 (2006).

9. F. Rodríguez-Trelles, G. Álvarez, C. Zapata, Genetics 142, 179 (1996).

10. Drosophila chromosomal polymorphisms have been proposed as indicators for monitoring evolutionary effects of global warming $(2-4,11,12)$, in part as a result of the regular seasonal cycles in inversion frequencies detected in a number of species $(9,13,14)$. Unlike other Drosophila species for which there is ample evidence for seasonality of their inversion polymorphisms $(9,14)$, data for $D$. subobscura are scarce, with the few studies comprising only one or two consecutive years, and few locations overall [reviewed in (9)]. A spectral decomposition into seasonal, long-term, and residual components of a temporal monitoring (four seasonal samples per year collected during two 4-year periods spanning 16 years) of the 0 chromosomal (the largest of the five acrocentric chromosomes of this species) polymorphisms in a Spanish population (9) disclosed a complex picture. Most common inversions (i.e., mean frequencies $\geq 0.05$ ) followed seasonal cycles superimposed on long-term trends. The relative weight of each component varied with the inversion, but seasonality was always the dominant factor, accounting for up to 50 to $60 \%$ of the total temporal variance of some gene arrangements. For instance, every midspring to early summer, $0_{\text {ST }}$ and $\mathrm{O}_{3+4+7}$ dwindled and rose on average to $\sim 0.5$ and 1.5 of their midspring frequencies (i.e., 0.1751 and $0.3960)$, respectively (9).

11. M. Levitan, W. J. Etges, BMC Evol. Biol. 5, 4 (2005).

12. A. A. Hoffmann, C. M. Sgró, A. R. Weeks, Trends Ecol. Evol. 19, 482 (2004).

13. T. Dobzhansky, Genetics 28, 162 (1943).

14. C. B. Krimbas, J. R. Powell, Eds., Drosophila Inversion Polymorphism (CRC Press, Boca Ratón, FL, 1992).

15. We thank B. Hawkins and three anonymous reviewers for their valuable comments on the manuscript. F.R.-T. is supported by contract Ramón y Cajal from the Ministerio de Educación y Ciencia (Spain).

13 October 2006; accepted 20 February 2007 10.1126/science. 1136298 